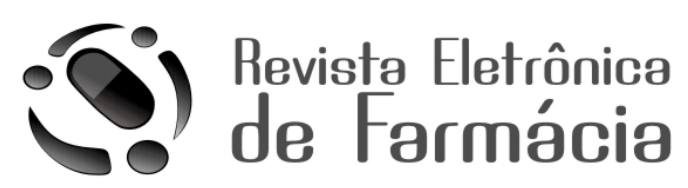

REF - ISSN 1808-0804 Vol. V (1), 101-110, 2008

\title{
ESTUDO ESPECTROFOTOMÉTRICO DA ATIVIDADE FOTO- PROTETORA DE EXTRATOS AQUOSOS DE ACHILLEA MILLEFOLIUM, BRASSICA OLERACEA VAR. CAPITATA, CYPERUS ROTUNDUS, PLECTRANTHUS BARBATUS, POROPHYLLUM RUDERALE (JACQ.) CASS E SONCHUS OLERACEUS
}

\section{Spectrophotometric study of the photoprotection activity of the Achillea millefolium, Brassica oleracea var. capitata, Cyperus rotundus, Plectranthus barbatus, Porophyllum ruderale (jacq.) Cass and Sonchus oleraceus Aqueous extracts}

\author{
Marcelo B. da Rosa, ${ }^{1,2}$, Tancredo G. de Oliveira, ${ }^{3,4}$, Camilo A. de Carvalho ${ }^{3,4}$, Fabiano D. Silva ${ }^{3,4}$ \\ Leandro M. de Carvalho ${ }^{5,6}$, Paulo C. Nascimento ${ }^{5,6}$, Rodrigo L. Peres ${ }^{3,6}$ \\ ${ }^{1}$ Centro Regional Sul de Pesquisas Espaciais, CRS/INPE, Cx. Postal 5021, 97015-970, Santa Maria, RS, Brasil. \\ ${ }^{2}$ Pesquisador do Laboratório de Exobiologia e Biosfera \\ ${ }^{3}$ Universidade Vale do Rio Doce - UNIVALE, 35020-220, Governador Valadares, MG, Brasil. \\ ${ }^{4}$ Acadêmico do Curso de Farmácia \\ ${ }^{5}$ Universidade Federal de Santa Maria, Cx. Postal 5051, 97015-970, Santa Maria, RS, Brasil. \\ ${ }^{6}$ Professor de Química Analítica
}

*Autor para correspondência: mbdarosa@lacesm.ufsm.br

Recebido em 16/01/2008 - Aceito em 17/07/2008

RESUMO: A radiação ultravioleta corresponde a $5 \%$ da radiação solar incidente na superfície terrestre e pode ser classificada como UV-A (320-400 nm), UV-B (290-320 nm) e UV-C (100-290 nm). Os danos causados pela radiação UV podem ser amenizados com o uso de substâncias denominadas filtros solares, encontrados em formulações tópicas, cujo fator de proteção solar pode ser calculado espectrofotometricamente. Neste estudo avaliou-se espectrofotometricamente o fator de proteção solar obtidos de extratos aquosos de Achillea Millefolium, Brassica oleracea var. capitata, Cyperus rotundus, Plectranthus barbatus, Porophyllum ruderale (jacq.) Cass e Sonchus oleraceus. Para o cálculo do fator de proteção espectrofotométrico considerou-se a região UV-A + UV-B, capaz de gerar eritematose. A análise espectral dos extratos a partir de uma concentração de 10\% (massa de planta triturada/volume de água) demonstrou que os extratos promovem fotoproteção nas regiões, tanto UV-A, quanto UV-B, resultando fatores de proteção solar em torno de 8 para Achillea, 6 para Sonchus, 5 para Porophylum e Brassica, 2 para Plectrantus e 1 para Cyperus. Portanto, acredita-se que os extratos estudados podem ser potencialmente empregados na produção de fitocosméticos com aplicação fotoprotetora, uma vez considerada a baixa concentração de extrato adotada para este estudo.

PALAVRAS-CHAVE: radiação UV, fitoterápicos fotoprotetores, estudo espectrofotométrico.

ABSTRACT: The ultraviolet radiation corresponds about $5 \%$ of the incident radiation on the terrestrial surface. This can be classified as UV-A $(320-400 \mathrm{~nm})$, UV-B $(290-320 \mathrm{~nm})$ and UV-C $(100-290 \mathrm{~nm})$. The damages caused by the UV radiation can be minimized using pharmaceutical formulations, photoprotectors, where the factor of solar protection involved in these formulations can be spectrophotometically estimated. In this work, a spectrophotometric study involving the photoprotection potential of Achillea Millefolium, Brassica oleracea var. capitata, Cyperus rotundus, Plectranthus barbatus, Porophyllum ruderale (jacq.) Cass and Sonchus oleraceus aqueous extracts is reported. For the spectrophotometric estimations of the factor of solar protection was 
Rosa, M. B. et al./Revista Eletrônica de Farmácia Vol 5(1), 101-110, 2008.

considered the UV-A + UV-B range, because the biogenic absorption of radiation in this range can generate erithema. The spectral analysis of the aqueous extracts using a dilution about $10 \%(\mathrm{~m} / \mathrm{v}$ : mass of triturated plant / volume of water) has demonstrated a photoprotection for all extracts, resulting factors of solar protection about 8 for Achillea, 6 for Sonchus, 5 for Porophylum and Brassica, 2 for Plectrantus and 1 for Cyperus. Therefore, these extracts can be potentially used in the production and/or incorporation of phytocosmetics.

KEYWORDS: UV radiation, photoprotectors phytoterapics, spectrophotometric study

\section{INTRODUÇÃO}

Nas últimas décadas o meio ambiente tem se manifestado de forma bastante clara quanto às agressões causadas pelo homem. Como existe uma tendência global de redução dos níveis do ozônio atmosférico, que funciona como um filtro para a radiação ultravioleta (UV), o interesse por este estudo tem despertado a atenção da comunidade científica quanto à possibilidade de haver um aumento na intensidade de radiação UV na superfície terrestre (KIRCHHOFF et al. et al, 2000; TAVARES et al., 2003). Os efeitos causados a saúde humana devido à ação solar são em sua maioria cumulativos e irreversíveis sendo capazes de produzir alterações normalmente imperceptíveis em curto prazo. Alterações como das fibras colágenas e elásticas (elastina), perda de tecido adiposo subcutâneo, fotocarcinogênese, foto-envelhecimento, câncer de pele, dano ao DNA (ácido desoxirribonucléico), apoptose (morte celular), acúmulo de proteína p53 responsável pelo reparo na estrutura do DNA lesado e mutação no gene p53 localizado no cromossomo 17 p132 supressor de tumor, são alguns entre os vários malefícios causados pelo excesso de exposição solar (CASTRO et al., 2006, BIHHHIMER, 1989; RIEGER, 1983; TAVARES et al., 2003; BINO et al., 2006).

Do ponto de vista de dano ao DNA, as mutações no gene p53 ocorrem em pontos onde o reparo do DNA é diminuído, impedindo que células lesadas entrem em apoptose. A radiação solar causa formação de dímeros de timidina no DNA e no ácido ribonucléico (RNA), resultando em mutações que provocam uma transformação de ordem neoplásica. $\mathrm{O}$ aumento da atividade da telomerase, enzima que acelera a telófase no ciclo mitótico, retarda a apoptose e prolonga a vida celular. As células mutantes continuam a acumular injúria genética, sendo achadas tanto nas ceratoses actínicas (ceratinócitos atípicos e pleomórficos) quanto em carcinomas espinocelulares. Citologicamente, ceratoses actínicas e carcinomas espinocelulares são praticamente indistinguíveis (CASTRO et al., 2006).

Tanto a radiação UV-A quanto UV-B agem sobre os sistemas vivos provocando alterações fisiológicas nos tecidos, como a indução da atividade de algumas enzimas, secreção de citoquinas e reparo ou recombinação de estruturas (ANVISA, 2002; Jornal Oficial da União Européia, 2006; DAVOLOS, 2007).

A radiação UV-A provoca danos considerados como mais leves e crônicos (STEINER, 1995). Caracterizase por não produzir eritema (queimadura) e apresenta uma modesta ação bactericida. Esta faixa espectral é responsável pelo bronzeamento imediato de curta duração (RANGEL \& CORRÊA, 2002). Já a radiação UV-B, causa danos agudos como queimaduras (STEINER, 1995; KIRCHHOFF et al., 2000; SOUZA, 2005), eritema e promove um bronzeamento tardio e de longa duração e, ainda, participa de duas das três etapas necessárias para a malignização carcinogênica: a iniciação e a promoção. A iniciação inclui eventos que facilitam a introdução de mutações nos ceratinócitos. Já a promoção envolve a repetitiva exposição da célula transformada a agentes químicos ou físicos, com efeito pró-inflamatório (CASTRO, 2006). Além disso, a radiação UV-B pode promover a biotransformação do ergosterol em vitamina D (TAVARES et al., 2003).

A Dose Mínima Eritematosa (DME) é definida como a dose mínima de radiação UV requerida para produzir a primeira reação eritematosa perceptível com bordas bem definidas, observadas entre 16 e 24 horas após a exposição à radiação UV (DAVOLOS et al., 2007). Estudos têm mostrado que, depois de uma DME, a quantia de DNA danosos será maior em peles claras comparadas à pele mais escura (BINO et al., 2006; DAVOLOS et al., 2007). BINO et al. avaliaram 42 tipos de pele considerando a distribuição de melanina classificada em eumelanina, responsável pela coloração marrom-preto e a feomelanina, pela amarelo-vermelho. Ambas estão situadas na camada basal da epiderme. Foi observado que indivíduos com fototipo de pele mais escura apresentavam pouca ou quase nenhuma alteração no DNA de células da epiderme basal, supra-basal e derme superior quando comparados aos de pele mais clara, de forma linear da pele clara para pele escura, quando mantido o mesmo tempo de exposição e intensidade à radiação UV induzida. Portanto, foi observado que um acúmulo maior da proteína p53 ocorre em indivíduos de pele mais clara. A partir dessas e outras avaliações (HAVSTEEN, 2002; DAVOLOS et al., 2007), como exame histológico, sugere-se que a melanina, em específico a eumelanina, presente em maior concentração na epiderme de pessoas com pele escura, promove proteção contra os fotodanos da radiação UV .

Segundo a Agência Nacional de Vigilância Sanitária (2002), o fator de proteção solar (FPS) é definido como sendo a dose mínima eritematosa na pele protegida dividida pela dose mínima eritematosa na pele não protegida e pode variar de acordo com os fototipos de pele (Tabela 1). 
Rosa, M. B. et al./Revista Eletrônica de Farmácia Vol 5(1), 101-110, 2008.

Conforme KIRCHHOFF et al. (2000); MUNAKATA, 2000 e DAVOLOS (2007) outros fatores também podem ser destacados: a sazonalidade da radiação UV, as diferenças com relação à latitude geográfica e altitude, freqüência e tempo de exposição, período do dia e condições climáticas.

O Jornal Oficial da União Européia (2006) divulgou que o grau mínimo de proteção solar pelos protetores solares deve ser: (a) uma proteção de fator UV-B com fator de proteção 6 , conforme se obtém na aplicação do método de ensaio do fator de proteção solar internacional, ou um grau de proteção equivalente obtido com qualquer método in vitro e (b) uma proteção UVA com fator de proteção UV-A que seja 1/3 do fator de proteção solar, conforme se obtém na aplicação do método de escurecimento persistente de pigmentos, ou um grau de proteção equivalente obtido com qualquer método in vitro.

A proteção efetiva contra a radiação ultravioleta, para os mais variados tipos de pele, está disponível em preparações cosméticas para uso tópico, contendo filtros solares químicos e/ou físicos, conhecidos como fotoprotetores (BIHHIMER, 1989, ANVISA, 2002). O desuso de protetores solares em função do custo elevado e aliado ao fato dos altos níveis de UV-B monitorados nos últimos anos no Brasil pode causar uma série de danos como é apresentado na Tabela 1.

Tabela 1. Fototipos de pele com relação às conseqüências da exposição solar.

\begin{tabular}{|c|c|c|c|}
\hline & Fototipos da pele & $\begin{array}{l}\text { Conseqüências da } \\
\text { exposição solar }\end{array}$ & $\mathrm{FPS}_{\text {recomendado }}$ \\
\hline 1 & $\begin{array}{l}\text { Pele clara, olhos } \\
\text { azuis, sardentos }\end{array}$ & $\begin{array}{c}\text { Sempre se queimam e nunca se } \\
\text { bronzeiam }\end{array}$ & $<20$ \\
\hline 2 & $\begin{array}{l}\text { Pele clara, olhos azuis, } \\
\text { verdes ou castanhos } \\
\text { claros, cabelos } \\
\text { loiros ou ruivos }\end{array}$ & $\begin{array}{l}\text { Sempre se queimam e, às } \\
\text { vezes, se bronzeiam }\end{array}$ & \multirow[t]{2}{*}{$\geq 12<20$} \\
\hline 3 & $\begin{array}{l}\text { Média da cor de pele } \\
\text { branca normal }\end{array}$ & $\begin{array}{l}\text { Queimam-se moderadamente, } \\
\text { bronzeiam-se moderadamente }\end{array}$ & \\
\hline 4 & $\begin{array}{l}\text { Média da cor de pele } \\
\text { branca normal }\end{array}$ & $\begin{array}{l}\text { Queimam-se muito pouco, } \\
\text { bronzeiam-se bastante }\end{array}$ & \multirow{2}{*}{$\geq 6<12$} \\
\hline 5 & Pele morena ou parda & $\begin{array}{l}\text { Raramente se queimam e } \\
\text { bronzeiam-se muito }\end{array}$ & \\
\hline 6 & Pele negra & $\begin{array}{l}\text { Nunca se queimam (profundidade de } \\
\text { pigmentos) }\end{array}$ & $\geq 2<6$ \\
\hline
\end{tabular}

(Fonte: TOVO, 2004)

Como os protetores solares são ainda inacessíveis à população de países subdesenvolvidos, como é o caso do Brasil, o conhecimento e uso de plantas medicinais representa, na maioria das vezes, o único recurso terapêutico de muitas comunidades e grupos étnicos (DI STASI, 1996). Cabe ressaltar que mais de 50\% da população brasileira, por falta de recursos, não têm acesso a medicamentos essenciais para o tratamento ou prevenção de doenças (SIANI, 2003), além do fato das plantas medicinais serem a única forma de cuidados primários da saúde (CARDOSO \& FONTELES, 1999).

Juntamente com o cenário atual da bioprospecção, faz-se necessário sistematizar o estudo de algumas espécies. Tendo em vista a agregação de conhecimento, resgateda biodiversidade nacional e identificação potencial de plantas com possível ação fotoprotetora, além das demais ações já discutidas e estudadas por inúmeros autores, algumas plantas são propostas neste estudo como ponto de partida para este enfoque, sendo apresentadas na seqüência:

- Achillea millefolium: é uma planta da família Asteraceae que tem sido utilizada como anti-bacteriana, antifúngica, anti-tumoral, cicatrizante, anti-oxidante, anti-edematosa (ISAAC et al. 2002; SWEETMAN, 2002).

- Brassica oleracea var. capitata: tem sido utilizada tanto interna como externamente como abstergente, produto utilizado para limpar ferimentos, e na forma de cataplasmas (papa medicamentosa que se aplica, entre dois panos, a uma parte do corpo inflamada) no tratamento das feridas. Relatos informam ainda o uso da Brassica sp a 
Rosa, M. B. et al./Revista Eletrônica de Farmácia Vol 5(1), 101-110, 2008.

mais de um milênio em processos de cicatrização de abscessos, cefalgias idiopáticas (dores de cabeça de causas desconhecidas), independentes de febre ou distúrbios intestinais, dores reumáticas e reumatóides, tumores, prevenção de tuberculose, auxílio em casos de afonia, desnutrição, anemia, enfermidades do estômago, úlceras internas, hemorróidas, alcoolismo, gota e reumatismo (BALBACH \& BOARIM, 1993; CARVALHO et al.; 2007);

- Cyperus rotundus: ARANTES (2005) observou que o composto isocurcumenol, extraído dos rizomas da Cyperus rotundus $L$. pode ser um agonista do receptor benzodiazepínico e modulador alostérico gabaérgico, indicando uma possível ação ansiolítica desta planta.

- Plectranthus barbatus: é utilizada no tratamento não específico de problemas do fígado, distúrbios gástricos, espasmos intestinais, dores do estômago, como purgativo (ROUNCE, 1933; JARRETT, 1950; JOHNS et al., 1990; KOKWARO, 1993; CÂMARA et al., 2003), no tratamento do sarampo(KOKWARO, 1993), dos dentes e gengivas (MEYERHOFF, 1978), infecções gastro-intestinais (BAERTS \& LEHMANN, 1989; GUPTA et al., 1993), infecções uro-genitais (RWANGABO, 1993; NEUWINGER,2000), malária (NEUWINGER, 2000; SCHLAGE et al., 2000; STEELE et al., 2002), em atividade antibacteriana, antiviral, antifúngica e antiinflamatória (ALASBAHI et al., 1999; COS et al., 2002; MATU \& STADEN, 2003);

- Porophyllum ruderale (jacq.) Cass: é utilizada como cicatrizante, antiinflamatória (SILVA et al., 1996), antifúngica (DEVINCENZI et al., 1996), antibacteriana, Leishmanicida, no controle da hipertensão arterial, picadas de ofídios e no tratamento de doenças reumáticas (MARQUESINI, 1996);

- Sonchus oleraceus: é considerada diurética e empregada contra anemia carencial, astenia e como auxiliar no tratamento de problemas hepáticos (CORREA et al., 1998).

Apesar das plantas citadas acima não serem utilizadas como fotoprotetoras, estas apresentam em sua composição metabólitos secundários potencialmente aplicáveis para este fim (HAVSTEEN, 2002). Conforme SIMÕES et al. (2004), a presença de flavonóides e taninos, presentes na maioria das angiospermas que absorvem radiação UV, podem apresentar altas absortividades molares $\left(\varepsilon / \mathrm{M}^{-1} \mathrm{~cm}^{-1}\right)$ para comprimentos de onda $(\lambda)$ que culminem com um FPS biologicamente efetivo (Figura 1). A faixa espectral apresentada na Figura 1, com máximo em $305 \mathrm{~nm}$, é a de maior relevância em termos de fotoatividade, pois é a faixa onde ocorre a maior indução a quebra de dímeros de ciclobutanopiridina encontrado no DNA epidermal, conforme descrito no relatório da Organização Mundial da Saúde (EHC 160, 1994). Assim, bandas de intensidade elevada $(\varepsilon=10.000-20.000)$ a $\lambda>210 \mathrm{~nm}$, podem corresponder a cetonas $\alpha, \beta$-insaturadas, dienos ou polienos. Quanto mais extenso for o sistema conjugado maior é o $\lambda_{\max }$ de absorção. Cetonas, ácidos, ésteres, amidas e outros compostos simples contendo sistemas $\pi$ de elétrons não ligantes produzem bandas de absorção com $\lambda_{\max }>300 \mathrm{~nm}$ com intensidade baixa e $\lambda_{\max }<250 \mathrm{~nm}$ com intensidade elevada. Em sistemas conjugados, pode-se observar desvios batocrômicos. Esse desvio pode ser verificado variando-se o pH da solução estudada (EWING, 1972; SKOOG, 2002).

Alguns antioxidantes como o betacaroteno, administrado via oral (180-300 mg/dia) tem ação comprovada na protoporfiria eritropoiética, controlando a fotossensibilidade, queimação, eritema e edema (CASTRO et al., 2006). Entretanto absorve luz em $\lambda>400 \mathrm{~nm}$. Além disso, devido a sua lipofilicidade, é pouco provável que esteja presente em soluções extrativas com solventes polares, descartando-se assim seu interesse neste estudo (SIMÕES et al., 2004).

Em relação a possíveis reações fototóxicas e fotoalérgicas, estas ocorrem quando substâncias químicas são transformadas em metabólitos tóxicos através da biotransformação enzimática. Os medicamentos absorvidos localmente para o interior da pele e os que chegam à pele através da circulação sistêmica podem ser o instrumento de reações fotoquímicas que ocorrem internamente: isso pode resultar em reações fotossensitivas induzidas quimicamente ou em um aumento dos efeitos usuais da luz solar. As tetraciclinas, o ácido nalidíxico, as sulfonamidas (antibióticos) e a clorpromazina (antipsicótico) são exemplos de substâncias químicas fototóxicas. Elas são amiúde inócuas à pele na ausência de exposição solar. Assim, o uso concomitante de alguns medicamentos fototóxicos ou fotossensibilizadores com protetores solares fitoterápicos de uso tópico, à base dos extratos aqui propostos, podem diminuir possíveis efeitos tóxicos promovidos pela radiação solar.

Os fotoprotetores tópicos diminuem a foto-reativação do herpes (causada pelo herpesvírus). Estudos em humanos evidenciaram que a imunossupressão por UV sobre a hipersensibilidade de contato foi prevenida pelo uso de fotoprotetores (KLAASSEM, 2005; CASTRO et al., 2006).

Por outro lado, as plantas são capazes de produzir diferentes substâncias tóxicas em grandes quantidades, como alguns alcalóides, cumarinas e outras provenientes do metabolismo secundário (HAVSTEEN, 2002; SIMÕES et al., 2004), aparentemente justificado para sua própria defesa contra vírus, bactérias, fungos e animais predadores. Tais substâncias vêm sendo estudadas e caracterizadas. Entretanto, são poucos os estudos toxicológicos e genotóxicos (xenobiótico - danoso ao DNA) dessas substâncias (FONSECA, 2004). Neste contexto, antes da comercialização de fitoterápicos fotoprotetores a avaliação de efeitos adversos e/ou tóxicos dos extratos abordados neste estudo, faz-se necessária, a fim de verificar em qual concentração produziria efeitos possivelmente nocivos à saúde humana. 
Rosa, M. B. et al./Revista Eletrônica de Farmácia Vol 5(1), 101-110, 2008.

A toxicidade dos extratos pode ser comparada com substâncias como o homossalato, (que em altas concentrações $(8 \%-\mathrm{m} / \mathrm{v})$ apresenta FPS 4), internacionalmente empregado e sem nenhum efeito adverso conhecido nessa concentração, salvo em pessoas com hipersensibilidade à essa substância. Portanto, pode-se validar o emprego dos extratos daquelas plantas que apresentaram FPS acima desse valor e na mesma concentração, com maior segurança em fitoterápicos fotoprotetores.

Apesar das incertezas envolvendo plantas e sua aplicabilidade em termos de fitocosméticos e fitofarmácos, sabe-se que os fitoterápicos apresentam efeitos adversos menos significativos que os de substâncias sintéticas e/ou isoladas, e por isso os extratos em estudo a concentração igual ou maior a 2,0mg/L podem vir a ser aplicados na produção de fotoproterores fitoterápicos, pois, a essa concentração, a probabilidade de agressão à pele é teoricamente inexistente.

Assim, a proposta deste trabalho é apresentar uma coleção de espectros de extratos de plantas amplamente usadas pela medicina popular e avaliar espectrofotometricamente sua potencial aplicação como possíveis fitocosméticos (fotoprotetores) utilizando a metodologia proposta por MANSUR et al. 1986 e citado recentemente por DAVOLOS, 2007.

\section{MATERIAIS E MÉTODOS}

\section{Material vegetal}

As plantas foram coletadas no horto do campus Antônio Rodrigues Coelho da Universidade Vale do Rio Doce, Governador Valadares, MG.

A coleta dos vegetais, para realização dos ensaios laboratoriais, restringiu-se as partes aéreas das plantas. Todo o material foi lavado em água corrente, seco em estufa à $40^{\circ} \mathrm{C}$ com umidade controlada. As plantas foram trituradas em moinho de facas (Marconi ${ }^{\circledR}$ - Modelo 340).

\section{Preparo dos extratos}

Do material seco e triturado, de cada planta separadamente, foram retirados $10 \mathrm{~g}$ para extração e utilizando água $(\mathrm{pH} 7,0)$ como solvente. A água utilizada no preparo das soluções e limpeza da vidraria foi de origem de filtro de osmose reversa (Permution ${ }^{\circledR}$ ). A extração foi realizada utilizando-se ultrasom por 60 minutos (Unique ${ }^{\circledR}$ MaxiClean 1400) à $28^{\circ} \mathrm{C}$.

\section{Prospecção fitoquímica}

Uma prospecção fitoquímica qualitativa extratos aquosos da Achillea Millefolium, Brassica oleracea var. capitata, Cyperus rotundus, Plectranthus barbatus, Porophyllum ruderale (jacq.) Cass e Sonchus oleraceus foi realizada com a finalidade de avaliar a presença de classes de compostos majoritários, conforme descrito em SIMÕES et al., 2004. Os testes se baseiam em reações cromáticas e de precipitação. Nesta prospecção avaliouse a presença qualitativa de açúcares redutores, compostos fenólicos, taninos, flavonóides, cumarinas, compostos antracênicos, heterosídeos cardiotônicos, saponinas, naftoquinonas, antraquinonas, triterpenos e esteróides.

\section{Análises espectrofotométricas}

Alíquotas de $1 \mathrm{ml}$ de cada extrato foram retiradas preparando-se uma soluções com a concentração final de $0,1 \%$ (v/v - extrato a 10\% / água). Um espectrofotômetro Femto 800 XI com cubeta de quartzo de $1 \mathrm{~cm}$ de caminho óptico foi usado para aquisição dos espectros. Varreduras de 220 a 400nm com intervalos de $2 \mathrm{~nm}$ foram realizadas.

\section{Cálculo do FPS}

Os cálculos foram realizados considerando os intervalos de $\lambda$ determinados por MANSUR et al., 1986. Os valores de $\mathrm{EE}(\lambda)$ e I $(\lambda)$ utilizados para o cálculo do FPS foram os mesmos usados da literatura. Aplicou-se o fator de diluição $\left(F_{d}\right)$ para correção de equivalência dos FPS dos extratos com os valores de referência.

$$
\text { FPS espectrofotométrico }=F C \cdot \sum_{290}^{320} E E(\lambda) \cdot I(\lambda) \cdot \operatorname{Abs}(\lambda)
$$

onde FC = fator de correção (10), determinado de acordo com os dois filtros solares de FPS conhecidos e testados em seres humanos de tal forma que um creme contendo $8 \%$ de homossalato originasse um FPS = 4; 
Rosa, M. B. et al./Revista Eletrônica de Farmácia Vol 5(1), 101-110, 2008.

$E E(\lambda)=$ efeito eritemogênico da radiação; $\mathrm{I}(\lambda)=$ intensidade do sol; abs $(\lambda)=$ leitura espectrofotométrica da absorvância da solução do filtro solar.

Para $\lambda$ próximos a $305 \mathrm{~nm}$ (Figura 1), pode ser observado uma faixa espectral restrita, na qual as contribuições erimatogênicas são apresentadas de acordo com sua intensidade relativa.

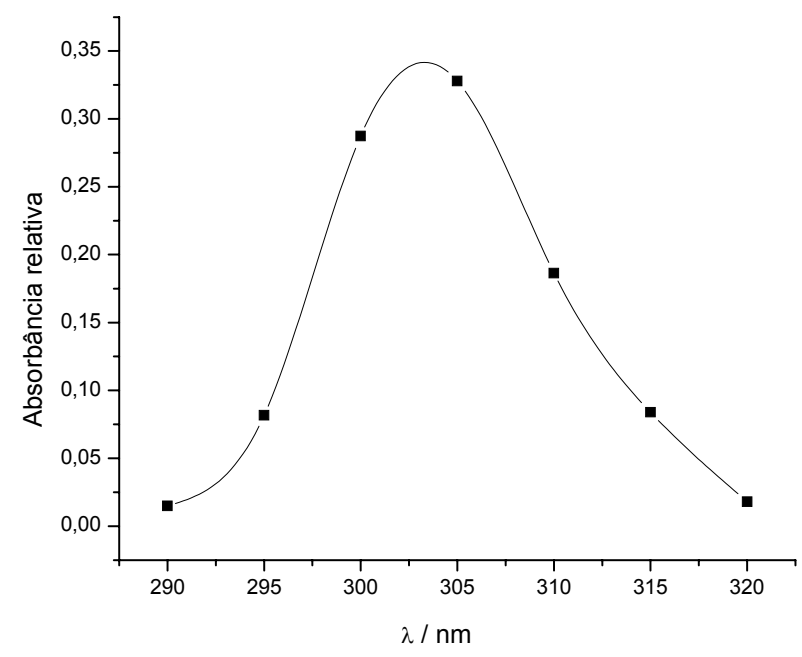

Figura 1. Esquema do efeito eritematogênico solar (Adaptado de MANSUR et al., 1986).

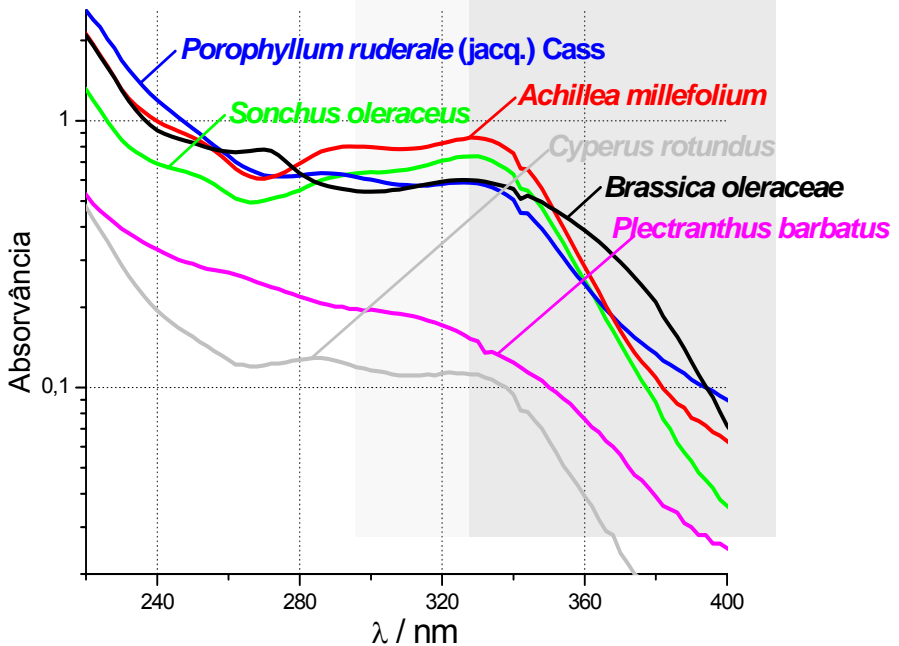

Figura 2. Espectro dos diferentes extratos aquosos sob a mesma concentração $(0,1 \% \mathrm{~m} / \mathrm{v})$.

\section{RESULTADOS E DISCUSSÃO}

Observando a Figura 2, quatro extratos se destacaram com maior absorção na faixa de UV-A e B, da Achillea, Sonchus, Brassica e Porophylum.

$\mathrm{Na}$ Tabela 2 são mostrados os valores de absorvância dos extratos aquosos para ambas faixas espectrais (UV-A + UV-B). Destes valores, uma média e desvio padrão (s.d.) para a faixa de 280 - 360nm foram calculados.

Estes valores são utilizados no cálculo posterior do FPS espectrofotométrico.

Tabela 2. Valores das absorvâncias dos extratos em água $1 \mu \mathrm{L} / \mathrm{mL}$ para todos os extratos estudados.

\begin{tabular}{c|c|c|c|c|c|c}
\hline & \multicolumn{7}{|c}{ Absorvância } \\
\hline$\lambda / \mathrm{nm}$ & Achillea & Sonchus & Brassica & Porophylum & Cyperus & Plectrantus \\
\hline 280 & 0,70 & 0,54 & 0,62 & 0,62 & 0,12 & 0,22 \\
\hline 300 & 0,79 & 0,64 & 0,55 & 0,59 & 0,11 & 0,19 \\
\hline 320 & 0,82 & 0,71 & 0,59 & 0,58 & 0,11 & 0,17 \\
\hline 340 & 0,75 & 0,64 & 0,56 & 0,52 & 0,09 & 0,12 \\
\hline 360 & 0,29 & 0,26 & 0,39 & 0,25 & 0,04 & 0,08 \\
\hline Média \pm s.d. & $\mathbf{0 , 6 7 \pm 0 , 2 1}$ & $\mathbf{0 , 5 6 \pm 0 , 1 8}$ & $\mathbf{0 , 5 4 \pm 0 , 0 9}$ & $\mathbf{0 , 5 2 \pm 0 , 1 5}$ & $\mathbf{0 , 1 0} \pm \mathbf{0 , 0 3}$ & $\mathbf{0 , 1 6 \pm 0 , 0 6}$ \\
\hline
\end{tabular}

A Figura 3 evidencia a potencialidade dos extratos da Achillea, Sonchus, Brassica e Porophylum em termos de absorvância média com potencial fotoprotetor para a faixa espectral do UV-A e B. 
Rosa, M. B. et al./Revista Eletrônica de Farmácia Vol 5(1), 101-110, 2008.

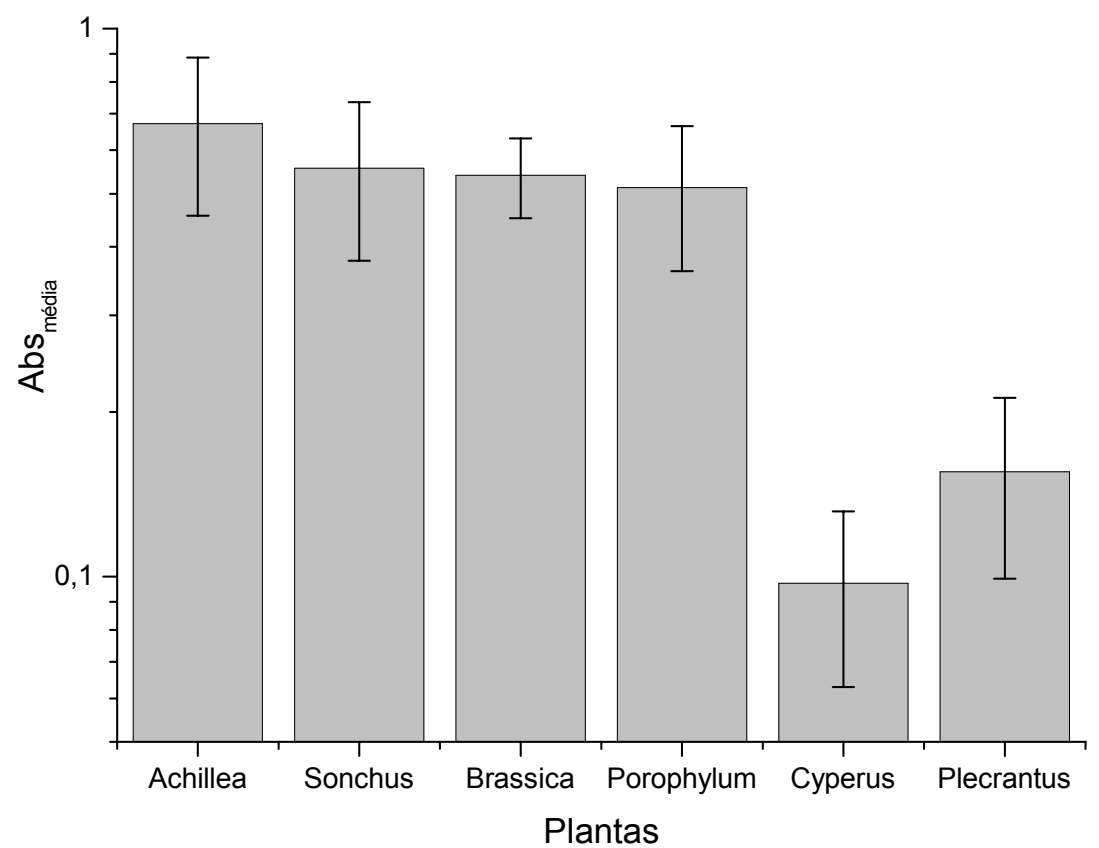

Figura 3. Absorvâncias relativas a proteção UV-A + UV-B (280 - $360 \mathrm{~nm})$ dos extratos aquosos.

Os resultados para o cálculo do FPS segundo a metodologia proposta por MANSUR et al., 1986, cujos valores de FPS referenciais e FPS dos extratos sem e com aplicação do $F_{d}$ são apresentados na Tabela 3.

Tabela 3. Cálculo do Fator de Proteção Solar espectrofotométrico para extratos aquosos.

\begin{tabular}{c|c|c|c|c|c|c|c}
\hline \multicolumn{2}{|c|}{} & \multicolumn{7}{c}{ Absorvância } \\
\hline$\lambda / n m$ & EE x I & Achillea & Sonchus & Porophylum & Brassica & Plectrantus & Cyperus \\
\hline 290 & 0,0150 & 0,81 & 0,62 & 0,62 & 0,55 & 0,19 & 0,12 \\
\hline 295 & 0,0817 & 0,81 & 0,62 & 0,61 & 0,54 & 0,19 & 0,12 \\
\hline 300 & 0,2874 & 0,79 & 0,64 & 0,59 & 0,54 & 0,19 & 0,11 \\
\hline 305 & 0,3278 & 0,79 & 0,65 & 0,58 & 0,54 & 0,19 & 0,11 \\
\hline 310 & 0,1864 & 0,77 & 0,66 & 0,56 & 0,56 & 0,19 & 0,11 \\
\hline 315 & 0,0839 & 0,79 & 0,67 & 0,57 & 0,57 & 0,18 & 0,11 \\
\hline 320 & 0,0180 & 0,82 & 0,71 & 0,58 & 0,59 & 0,17 & 0,11 \\
\hline$\sum_{290-320 n m}$ & 0,79 & 0,65 & 0,58 & 0,55 & 0,19 & 0,11 \\
\hline \multicolumn{2}{r|}{ FPS $_{\text {média }}$} & $\mathbf{8}$ & $\mathbf{6}$ & $\mathbf{5}$ & $\mathbf{5}$ & $\mathbf{2}$ & $\mathbf{1}$ \\
\hline FPS $^{*}\left(\mathrm{~F}_{\mathrm{d}}=5\right)$ & 2 & 1 & 1 & 1 & 0 & 0 \\
\hline FPS $_{\text {ref }}=5,6 \pm 5,3$ \\
\hline
\end{tabular}

$\Sigma_{290-320 \mathrm{~nm}}=$ soma das absorvâncias dos extratos multiplicada pelo valor de EE $\mathrm{x}$ I relativo a cada $\lambda$, FPS $=$ calculado para os extratos; FPS ${ }^{*}=$ calculado para os extratos aplicando-se o fator de diluição equivalente aos fatores de referência; FPS $_{\text {ref }}=$ média calculada para 11 dos filtros com FPS proposto por MANSUR et al., 1986. a Todas os extratos foram preparados a $0,1 \%$ (v/v - extrato a $10 \%$ / água).

Quanto ao resultado da prospecção fitoquímica, todos os extratos aquosos estudados indicaram a presença de compostos fenólicos, taninos, flavonóides, cumarinas, heterosídeos cardiotônicos, açúcares redutores, triterpenos e esteróides. Isso evidencia que a presença de metabólitos secundários assume uma posição de destaque em termos da absorção espectral de determinados extratos pela radiação solar na faixa do UV-B, amplamente discutida por HARBORNE \& WILLIANS, 2000; HAVSTEEN, 2002, TSAO \& DENG, 2004 e GOBBONETO \& LOPES, 2007. 
Rosa, M. B. et al./Revista Eletrônica de Farmácia Vol 5(1), 101-110, 2008.

CONCLUSÃO

Acredita-se que as plantas propostas neste trabalho podem ser potencialmente empregadas de forma isolada ou conjuntamente como ativo principal ou adjuvante em concentrações apropriadas (maiores que $10 \%$ $\mathrm{m} / \mathrm{v}$ ). Em preparações fotoprotetoras tópicas, onde são aplicadas quantidades recomendadas de $2 \mathrm{~mL} / \mathrm{cm}^{2}$ sobre a pele, ou na forma de cápsulas, devido a ação antioxidante dos flavonóides presentes nesses extratos, estes poderiam ser utilizados. Como os flavonóides, por natureza, neutralizam espécies químicas reativas de oxigênio, que são causadoras de doenças cardiovasculares, câncer e degeneração celular influenciados pela radiação solar, o estudo destes extratos se ratifica.

Portanto, estudos como este são importantes, uma vez que norteiam a seleção de espécies vegetais que apresentem um potencial fator de proteção solar de forma simples e com baixo custo.

Assim, os extratos citados que apresentaram FPS comparativo $>4$ em relação ao homossalato, podem vir a ser aplicados com a mesma finalidade, desde que sua produção siga a legislação vigente de comercialização de filtros solares.

\section{AGRADECIMENTOS}

Os autores agradecem a FAPEMIG (CAG-1985/05) e ao CNPq (385524/2006-4) pelo suporte financeiro.

\section{REFERÊNCIAS BIBLIOGRÁFICAS}

ALASBAHI, R.H.; SAFIYEVA, S.; CRAKER, L.E.. Antimicrobial activity of some Yemeni medicinal plants. Journal of Herbs, Spices and Medicinal Plants. n. 6, p. 75-83, 1999.

ARANTES, M. do C. B. et al. Estudo farmacognóstico do Cyperus rotundus L. Rev. Elet. de Farm. v 2 , n. 2, p. 1720, 2005.

BAERTS, M.; LEHMANN. J. Guérisseurs et plantes médicinales de la région des Zaire-Nil au Burundi. Musée Roy. De l'Afrique Centrale Tervuren, Belgique. Annales des Sciences Economiques 18, 1989.

BALBACH, A; BOARIM, D. As Hortaliças na Medicina Natural. $2^{\text {a }}$ Ed. Itaquacetuba: Vida Plena, 1993. 2880p.

BIHHIMER W. L. Avaliação de filtros solares em seres humanos: proteção contra a queimadura solar. Cosmet Toil (edição em português). v. 1, p. 41-48, 1989.

BINO, S. Del; SOK, J.; BESSAC, E.; BERNERD F. Relationship between skin response to ultraviolet exposure and skin color type. Pigment Cell Res. n. 19, p. 606-614, 2006.

BRASIL. Agencia Nacional de Vigilância Sanitária (ANVISA). Resolução RDC $n^{\circ} 237$. Dispõe sobre: Regulamento Técnico Sobre Protetores Solares em Cosméticos. 22 de agosto de 2002.

CÂMARA, C. C. et al. Antispasmodic effect of the essential oil of Plectranthus barbatus and some major constituents on the guinea-pig ileum, Planta. Medica. v. 69, p. 1080-1085, 2003.

CARDOSO, J. H. L.; FONTELES, M. C. Pharmacological effects of essential oils of plants of the northeast of Brazil. An. Acad. Bras. Cienc. v. 71, p. 207-213, 1999.

CARVALHO, C. A. et al. Estudo espectrométrico da concentração global dos constituintes químicos para diferentes estágios fenológicos das folhas de Brassica oleracea variedade capitata (Brassicaceae). 2007. $65 \mathrm{f}$. Monografia (Graduação) - Universidade Vale do Rio Doce. Governador Valadares, 2007.

CASTRO, I. A. de; SCHÜTZ, E. C.; BAKOS, L.. Ceratoses actínicas. Rev HCPA. v. 2, n. 26, 2006.

CORREA, A. D. et al. Plantas Medicinais: do cultivo a terapêutica. ed.2ª Petrópolis: Editora Vozes. 1998.

COS, P. et al. Evaluation of Rwandan medicinal plant extracts for their antimicrobial and antiviral activities. Journal of Ethnophannacology. n 79, p. 155-163. 2002.

DAVOLOS, J. F.; DAVOLOS, M. R.; CORREA, M. A.. Protetores Solares. Quim. Nova, v. 30, n. 1, p. 153-158, 2007. 
Rosa, M. B. et al./Revista Eletrônica de Farmácia Vol 5(1), 101-110, 2008.

DEVINCENZI, I.A.A. et al. Atividade fungitóxica e citotóxica do óleo essencial de Porophyllum ruderale. In: SIMPÓSIO DE PLANTAS MEDICINAIS DO BRASIL, 14, Florianópolis, SC, 1996. Anais. Florianópolis, SC: UFSC, 1996.

DI STASI, L. C. Plantas Medicinais: arte e ciência. São Paulo: Unesp, 1996. 230p.

ECH 160: Ultraviolet radiation, Report of the World Health Organisation, WHO Library, Geneva, 1994, 353p.

EWING, G. W. A absorção de radiação: ultravioleta e visível. In: Métodos Instrumentais de Análise Química. São Paulo: Edgard Blücher, 1972. Cap.3, p. 41-88.

FERRADEIRA, I. S. et al. Levantamento do uso da pomada de Brassica sp. no município de Governador Valadares. In: PESQUISA CIENTÍFICA E PÓS-GRADUAÇÃO STRICTO SENSU NAS INSTITUIÇÕES DE ENSINO SUPERIOR, 2003, Governador Valadares. Anais do Simpósio de Pesquisa e Iniciação Científica. Governador Valadares: UNIVALE, 2003. p. 116.

FONSECA, C. A.; PEREIRA, D. G. Aplicação da genética toxicológica em plantas com atividade medicinal. Infarma. v.16, n. 7-8, p. 51-54, 2004.

GOBBO-NETO, L.; LOPES, N. P. Plantas medicinais: fatores de influência no conteúdo de metabólitos secundários. Química Nova, v. 30, n. 2, p. 374-381, fev, 2007.

GUPTA. S., YADAVA, J.N.S., TANDON, J.S. Antisecretory (antidiarrhoeal) activity of Indian medicinal plants agianst Escherichia coli-enterotox-induced secretion in rabbit and guinea pig ileal loop models. International Joumal of Pharmacognosy. n. 31, p. 198-204, 1993.

HARBORNE, J. B., WILLIANS, C.A. Advances in flavonoid research since 1992. Phytochemistry, v. 55, p. 481$504,2000$.

HAVSTEEN, B. H. The biochemistry and medical significance of the flavonóides. Pharmacology \& Therapeutics, v. 96, p. 67-202, 2002.

ISAAC, V. L. B. et al. Atividade antiinflamatória tópica de cremes contendo óleo essencial de Achillea Millefolium L. ( Asteraceae). In: Jorge, L.I.F.; Pregnolatto, B.P.; Chicourel, E.L.; Zamariolli, L.A.; Graciano, R.A.S. Anatomy and evaluation of the antimicrobian activity in vitro of yarrow (Achillea Millefolium L). Rev. Cienc. Farm.. n. 20, p. 49-58, 1999.

JARRETT, P. Barbatus Andr. Herbarium specimen held at K collected from Uganda (Jarrett 16$), 1950$.

JOHNS, T., KOKWARO, J. O., KIMANANI, E. K.. Herbal remedies of the Luo of Siaya District, Kenya: quantitative criteria for consensus. Economic Botany. n. 44, p. 369-381, 1990.

KIRCHHOFF, V. W. J. H. et al. A Variação Sazonal da Radiação Ultravioleta Solar Biologicamente Ativa. Brazilian Journal of Geophysics. v. 18, n. 1, 2000.

KLAASSEN, C. D. Princípios de toxicologia e tratamento do envenenamento. In: GILMAN, A. F.; HARDMAN, J. D.; LIMBIRD, L. E.; et al.. As bases farmacológicas da terapêutica. Petrópolis, RJ: Interamericana do Brasil Ltda, 2005. p. 51-61.

KOKWARO. J. O., 1993. Medicinal Plants of East Africa second Literature Bureau. Nairobi.

MANSUR, J. de S.; BREDER, M. N. R.; MANSUR, M. C. d'A. Dterminação do fator de proteção solar por espectrofotometria. An. Bras. Dermatol. v. 3, n. 61. p. 121-124. 1986.

MARQUESINI, N. R. Plantas usadas como medicinais pelos índios do Pará e Santa Catarina, Sul do Brasil. Família Asteraceae. In: SIMPÓSIO DE PLANTAS MEDICINAIS DO BRASIL, 14, Florianópolis, 1996. Anais. SC: UFSC, 1996.

MATU, E. N.; VAN STADEN, J.. Antibacterial and anti-inflammatory activities of some plants used for medicinal purposes in Kenya, Jorn. Ethnopharmacol. v.1, n. 87, p. 35-41, 2003. 
Rosa, M. B. et al./Revista Eletrônica de Farmácia Vol 5(1), 101-110, 2008.

MEYERHOFF, 1978. P. barbatus Andr. Herbarium specimen held at K collected from Kenya (Meyerhoff 28 M).

MUNAKATA, N. et al. Comparisons of Spore Dosimetry and Spectral Photometry of Solar-UV Radiation at Four Sites in Japan and Europe. Photochemistry and Photobiology. v.6, n. 72. p. 739-745. 2000.

NEUWINGER, M. N.. African Traditional Medecine: A Dictionary of Plant Use and Aplplications. Medpharm Scientific Publishers, Stuttgart. p. 406-408, 2000.

RANGEL V. L. B. I.; CORRÊA, M. A. Fotoproteção. Cosmet Toil (edição em português). n. 14, p. 88-95, 2002.

RIEGER, M. M. The chemistry of tanning. Cosmet Toil. n. 98, p. 47-50. 1983.

ROUNCE, P. barbatus Andr. Herbarium specimen held at K collected from Tanzania (Rounce 253), 1933.

RWANGABO, P.C., 1993. La médicine traditionnelle au Rwanda. Edition Karthala. ACCT.

SCHLAGE, C.H. et al. Medicinal plants of Washambaa (Tanzania): documentation and ethnopharmacological evaluation. Plant Biology. n. 2, p. 82-92, 2000.

SIANI, C. A. Desenvolvimento Tecnológico de Fitoterápicos. Rio de Janeiro: Scriptorio Comunicações, 2003. 92p.

SILVA, S. A. R., ARAÚJO, L. C. L., AKISUE, M. K. Estudo das atividades farmacológicas (antiinflamatória e anticerogênica) e determinação da toxicidade aguda do extrato bruto hidroalcoólico de Porophyllum ruderale (JACQ.) Cassini. In: SIMPÓSIO DE PLANTAS MEDICINAIS DO BRASIL, 14, Florianópolis, 1996. Anais... SC: UFSC, 1996.

SIMÕES, C.O. et al. Farmacognosia da Planta ao Medicamento. $5^{\mathrm{a}}$ ed. Porto Alegre/Florianópolis: Editora UFRGS/ Editora UFSC, 2004. 1102p.

SKOOG, D. A. et. al. Aplicações de Espectrometria de Absorção Molecular no Ultravileta/Visível. In: de análise instrumental. 5 ed. Porto Alegre: Bookman, 2002. Cap.14, p. 300-321. Princípios

SOUZA, T.M. et al. Avaliação da atividade fotoprotetora de Achillea millefolium L. (Asteraceae). Rev. Bras. de Farmacognosia. v. 1. n. 15. p. 36-38. 2005.

STEELE, J.C. et al. Two novel assays for the detection of haemin-binding properties of antimalarials evaluated with compounds isolated from medicinal plants. Journal of Antimicrobial Chemotherapy. n. 50, p. 25-31, 2002.

STEINER, D. Envelhecimento cutâneo. Cosmet Toil (edição em português). n. 7, p. 29-32. 1995.

SWEETMAN, S. C. Martindale: The complete drug reference. 33a ed.. London, Pharmaceutical Press: 2002. p.1572.

TAVARES, A. et al. Solários: recomendações importantes. ORGANIZAÇÃO MUNDIAL DE SAÚDE, 2003.

TOVO, L. F. Radiação UV e fotodano cutâneo. Disponível em:

http://www.ambiente.sp.gov.br/prozonesp/apresentacao_tovo2004a.pdf [capturado em: 12 de junho de 2007].

TSAO, R., DENG, Z. Separation procedures for natturally occuring antioxidant phytochemicals. Journal of Chromatography B, v. 812, p. 85-99, 2004.

UNIÃO EUROPÉIA. Jornal Oficial da União Européia. L 265/39. Recomendação da comissão relativa à eficácia e às propriedades reivindicadas dos protetores solares. 22 de Setembro de 2006.

WEECHARANGSAN, W. et al. Antioxidative and neuroprotective activities of extracts from the fruit hull of Mangosteen (Garcinia mangostana Linn.). Med Princ Pract. v. 15., p. 281-287. 2006. 